\title{
Do You Want to Watch a Movie? Conceptualizing Video in Qualitative Research as an Imaginative Invitation
}

\author{
Sara Scott Shields ${ }^{1}$ \\ Florida State University \\ skshields@fsu.edu \\ Leslie Rech Penn \\ University of Georgia \\ krech@uga.edu
}

\begin{abstract}
This paper is positioned as a reflective exploration of the question: How might we use video representation as an imaginative invitation? We begin with a brief introduction, contextually situating ourselves within the world of image and arts-based practices. Then explore theoretical literature surrounding representation and our own understanding of what representation is and is not. Following this we ask, how might we use video representation as an imaginative invitation? Here we explore the potential for video to capture the movements of research and challenge how this might shift our ontological understanding of what it means to present research findings, by conceptualizing representation as an invitation to participate. Finally, as an analytic exercise, we invite you to watch a video with us, offering our discussion of the video as an attempt to demonstrate how a viewer might respond to a video invitation. In closing, we challenge you to explore the potential for video to become an imaginative invitation in your own work.
\end{abstract}

Keywords: video research; representation; imaginative invitation

\footnotetext{
${ }^{1}$ Biographical statements: Sara Scott Shields, PhD is an Assistant Professor of Art Education at Florida State University in Tallahassee, FL. Sara currently serves as the editor of The Journal of Art for Life and as the director of the MS in Art Education program at FSU. She received her BFA in Ceramics and Art Education and her MaED in Art Education from East Carolina University, later receiving her PhD in Art Education from The University of Georgia. Before working as an Assistant Professor, she worked for six years as a high school art teacher in Wilmington, NC. All of her research endeavors explore the question: How are the arts uniquely positioned to address the development of pedagogical and scholarly identities?

Leslie Rech Penn holds a tenured faculty position at South Carolina State University. She received a Bachelor of Arts in English from the University of Illinois, Champaign-Urbana in 1995 and a Master of Fine Arts in Studio Art from the University of South Carolina in 1998. Her artwork has been featured on the cover of CALYX: A Journal of Art and Literature by Women and she has been awarded fellowship grants from the Women's Studio Workshop in Rosendale, New York and the Fundacion Valparaiso in Mojacar, Spain. She is currently completing her doctoral work in Early Childhood Education at the University of Georgia. The majority of her work over the last twenty years has addressed the relationships between text and image.
} 
In the early 1970 s and into the $90 s^{2}$ philosophical and ethnographic worlds encountered a "crisis of representation" (Lincoln \& Denzin, 1994, p. 9; Marcus \& Fischer, 1986, p. 7). During this time, the world of qualitative research opened up to include a deep and meaningful exploration of the guiding epistemological, ontological and axiological values inherent in inquiry (Flaherty, Denzin, Manning, \& Snow, 2002). Scholars began exploring the how and why of representation in the context of qualitative research. This paper is positioned as a revisiting of that line of inquiry. In the following pages, we investigate the role of representation in arts based research and postulate the medium of video as a means for opening up new ontological possibilities for how we represent and understand research findings. We explore the idea of video as an imaginative invitation for the viewer/audience to collaborate and engage in inquiry with researchers. In our inquiry, two questions push at the boundaries of possibilities for qualitative research:

\section{What is representation?}

How might we use video representation as an imaginative invitation?

We begin with a brief introduction, contextually situating ourselves within the world of image and arts-based practices. Then, we engage in an exploration of the first question, exploring theoretical literature surrounding representation and our own understanding of what representation is and is not. Following this we ask, how might we use video representation as an imaginative invitation? Here we explore the potential for video to capture the movements of research and challenge how this might shift our ontological understanding of what it means to present research findings, by conceptualizing representation as an invitation to participate. Finally, as an analytic exercise, we invite you to watch a video with us, offering our discussion of the video as an attempt to demonstrate how a viewer might respond to a video invitation. In closing, we challenge you to explore the potential for video to become an imaginative invitation in your own work.

\section{Who We Are}

Neither my self nor my narrative can have, therefore, a single strand. I stand at the crossing point of too many social and cultural forces; and, in any case, I am forever on my way. My identity has to be perceived as multiple.

(Greene, 1995, p. 1)

Before beginning to dissect the role of representation and video in designing imaginative research invitations, we felt it important to share a bit about how we came to video representation in the first place. What follows is a

\footnotetext{
${ }^{2}$ Some might argue this crisis of representation is still occurring (Flaherty et al., 2002), although scholars like Rabinow (1986) and Van Maanen (1995) disagreed.
} 
brief exploration of who we are and how we see the world, because we feel the answers to these questions are the most important strands in our identities as researchers interested in video methodology.

In most traditional research programs graduate students are asked to engage in a series of courses focused on developing a set of research skills. For us, those skills were of the qualitative variety. Within philosophies ranging from pre-Socratic to postmodern, qualitative methodology courses at our university focused on the skills to acquire, manage, engage, explore, and present our data to readers ${ }^{3}$. While these tools were invaluable for us as burgeoning researchers, they also bumped up against our shared histories as artists. Throughout our studies, we continued to ask: What do the tools of qualitative work do for our nuanced and individual interpretations of the world? Are there other tools, methods, or practices that could work as well, or better?

In searching for answers to these questions we discovered arts based research (Barone, \& Eisner, 1997; Irwin, Kind, \& Springgay, 2005; Knowles, 2007; Leavy, 2015; McNiff, 1998; Rolling, 2013). Because of our shared backgrounds as artists, this ontological, epistemological, and methodological approach allowed us to better conceptualize not just our role as artist/researchers, but also the role of the viewer/audience. Inherent in the practice of making art is an awareness that the medium often carries a message (McLuhan, \& Fiore, 1967). The stroke of a paintbrush dipped in watercolor and swept across surfaces sends a different message than the audible crunch of a dry brush as it scrapes and scratches paper. Even without artistic training this rings familiar; think for a minute of the emotive quality of Jackson Pollock's famous spatters across the canvas of Number 11, juxtaposed with Monet's renowned paint strokes in Waterlilies. Both of these paintings done on canvas, both in oils, yet the paint conveys something completely different in each painting. This ability for media to manifest in different ways for different artists, and again for different viewers, is what makes art such an interesting vehicle for examining the complex concept of representation.

In the artistic sense, representation is often the manifestation of experience in tangible or sensory forms. Further, there is an implicit understanding that the artist's representation and interpretation are but one of many. While we may never know the artists exact interpretation, we can construct our own through viewing the final representation of what may have begun with a conceptual idea.

The power of the arts as a tool for inquiry opens up new possibilities for representing and interpreting the world around us. As Eisner suggests, "We seek out the arts in order to take a ride on the winds that art forms provide...secured largely through our sensory response[s]" (2008, p. 3-4). This

\footnotetext{
${ }^{3}$ It is important to note that our graduate education occurred in a university steeped in the belief that theory and practice are inextricably linked.
}

Do You Want to Watch a Movie? Conceptualizing Qualitative Research as Imaginative Invitation 
interest in the affective qualities of the arts is crucial to our thinking. We acknowledge and embrace the arts' ability to provide venues for new ways of knowing and new forms of knowledge. Not all knowledge is rooted in the concrete or tangible; in fact, most of the world around us is experienced, sensed, and felt. These are the phenomena the arts are suited to explore. We do not argue that arts based research or image based practice are the only ways of knowing our world, but rather, they are additional ways of experiencing, inquiring, representing and interpreting it (Eisner, 2008). With an understanding of who we are and the kinds of research practices we are interested in, we now shift the discussion back to the issue of representation.

\section{What is Representation?}

Within the global community, it is no longer possible to describe others as being part of a scientific endeavor without addressing what is commonly referred to as the crisis of representation - the dilemma we face when we try to represent others and ourselves as we crisscross boundaries of gender, race, identity, culture, time and location.

(Goldman, 2007, p. 4)

For years, positivist views of research assumed there was a universal way of representing the world around us. Building on this assumption, was a belief that within representations there lie a single, indisputable truth. Truth was understood to be a thing, an idea coinciding with and explaining reality. As time passed, interest shifted toward the role of language in our formation of understanding and thus knowledge. This shifted attentiveness from single version truths, to multifaceted forms of knowing (Flaherty et al., 2002; Greene, 1994). With increased consideration of the role of language in the formation of understanding, came a reciprocal interest in how representations are informed by the language systems inherent in them (Bakhtin, 1982). This gap between the positivist and post-positivist concepts of knowledge makes it difficult to establish the nature of representation (Goldman, 2007). Key questions addressed by theorists (Eisner, 1997; Fish, 1980; Flaherty et al., 2002; Greene, 1994; Pink, 2001; Rabinow, 1986; van Maanen, 1995) across disciplines are: 1) Is representation the manifestation of truth or is it merely one of the varied vantage points present at any given time? 2) Do we represent absolute ideas or are our representations immersed in context and story?

Representation might be simply defined as "stand[ing] for something else" (Goldman, 2007, p. 17). Through interpretation, representations (as symbols) and what they refer to, become inextricably linked. With this understanding then, "representations are not things, but rather processes" (Goldman, 2007, p. 18). Essentially, the process of representation occurs when we link a symbol or sign to a concept that emerged from an experience. Because of the interrelatedness of the symbol/context/thing, our interpretation is always shifting the outcome of 
the representative/interpretive equation. This constant changing of vantage points and shifting of elucidations results in multiple interpretations of the same representation.

Within our research settings and in the writing up of our findings, we are engaging in acts of interpretation in which representation becomes inevitable. Data itself is both an interpretation and representation; photographs are sprinkled with varying vantage points, transcripts are dusted with personal experience and artifacts are dredged through symbol systems. How then might we link actual events and our interpretations of those events with a representative counterpart in ways that honor our individual experience and make room for other possible interpretations? This question has been asked in various forms over the last 30 years or so. For example, Fish asked, "What makes an interpretation acceptable?" (1980, p. 338); Flaherty, et al. asked, "What is the relationship between observation and interpretation?" (2002, p. 481); and Greene asked, "What happens when we can no longer trust in the mediation of language, when the best consciousness can do is grasp the appearances of things - telling us nothing of a representable realm beyond" (1994, p. 209). Inspired by Greene's question doubting the mediation of language, we were moved to attempt a response by conceptualizing representation as an imaginative invitation asking the viewer/audience to participate in the interpretive processes, rather than crafting definitive representative products.

\section{What is an Imaginative Invitation?}

I also begin to seek out ways in which the arts, in particular, can release imagination to open new perspectives, to identify alternatives. The vistas that might open, the connections that might be made, are experiential phenomena; our encounters with the world become newly informed. When they do, they offer new lenses through which to look out at and interpret...

(Greene, 1995, pp. 17-18)

Because the image is what unites us as researchers and artists, we have consciously sought out image-based invitations in our work. Image and arts based practices in qualitative research are not a new development. On the tails of the representative debate, the arts emerged as a viable means to challenge what representation meant (Pink, 2001). These approaches assume knowledge is evolving, because we continue to know through doing (Dewey, 1934). Methodological approaches like arts based research, visual ethnography, and visual research methods (to name a few) all surfaced as new ways for engaging in inquiry (Knowles \& Cole, 2008). These approaches embrace the ability of the image to share nuances, evoke empathy, and allow new perspectives that illustrate our capacity to engage with life (McNiff, 2008). It is this idea of the image as an affective site of individual experience we are most attentive to, and it is this idea that brought us to the writing of Maxine Greene. 
Maxine Greene $(1995,2001,2005)$ was a clear voice advocating for the inclusion of the arts in educative experiences. Her work seamlessly wove scholarly theorizing with examples from the fine and literary arts, forcing the reader to embody the words on the page by imagining the works of art she referenced, essentially inviting the reader into her writing. While we are not relegating the importance of the arts to the field of education, we do see strong parallels between the world of education and the world of research. These two worlds feed into one another. As an interest in quantitative, numeric and defendable outcomes became the focus of research, including educational research, for instance, schools began to quantify student experiences through standardized testing, merit pay and national report cards (Greene, 1995). This interest in the quantifiable nature of experience brings us back to the rupture started by social scientists during the crisis of representation, and to the question: varied?

How do we represent experiences that are by nature ever changing and

It is this question we feel Greene's writing on imagination begins to address; we see her work in both educational research and debate on representation as extending an imaginative invitation to engage in teaching and scholarship aimed at re-imagining outcomes. We are drawn to the concept of the imaginative invitation, the open request to engage in the action of forming new ideas. More importantly though, we draw inspiration from her natural ability to invite the reader into her work, to encourage the reader to question and seek out their own understandings. The work of the imagination is centered on the opportunity to look at the world as if it might be different than it is, and within this imaginative action, there is an acknowledgement of the contingency of the view, essentially the role of personal context. Greene states, "To tap into imagination is to become able to break with what is supposedly fixed and finished, objectively and independently real" $(1995$, p. 19). This is where the concept of the imaginative invitation collides with representation. If we can conceive of our research as an imaginative invitation, we might open our work up to multiple interpretations and representations. We might trust our audience to contribute to our work. These alternative interpretive spaces become sites of resistance, where we find ourselves resisting the hegemony of the written word (Greene, 1991; hooks, 1990). While we acknowledge the importance of writing in the scholarly process, words (in didactic form) do not always accomplish what the arts $\mathrm{do}^{4}$. The arts invite the audience to participate, to move from the center to the margins in hopes that "they may recognize some of the ways in which consciousnesses touch and refract and engage with one another" (Greene, 1991, p. 29).

\footnotetext{
${ }^{4}$ We see a distinction between literary composition and scholarly writing. We do not mean to generalize all scholarly writing at non-literary; we openly acknowledge the work of scholars working to push language into new spaces.
} 


\section{How Might we use Video Representation as an Imaginative Invitation?}

Building on the possibilities inherent in arts based research and the possibilities of the imaginative invitation, we move this inquiry into exploring how we question the boundaries of representation in our own work with video. Because we are both artists, we are constantly pushing ourselves to discover new ways of interpreting and representing our research endeavors. In this search for new, artful ways of engaging the research experience, we came to video as a form of inquiry. For us, video as a mode of inquiry assumes representation and interpretation are process-based experiences. By thinking of representation as an imaginative invitation and interpretation as an imaginative act, we can begin to see the work we do, as an ontological pursuit, a way of living and doing research. As Greene (1991) reminds us, this artful representation would not be possible:

without the release of the imagination, the capacity to look through the windows of the actual...imagination may be the primary means of forming an understanding of what goes on under the heading of "reality;" imagination may be responsible for the very texture of experience. (p. 30)

While we create different kinds of videos, our shared interest in video as a form of representation brought us together to explore the representative possibilities inherent in video. Our attention to the possibilities of video encourages viewers to see them as expressive objects; much like traditional art making, we view our videos as affective sites of knowledge production. When opening up research representation and interpretation to this possibility, we found "video-based research artifacts are not just external visual representations, but can also be re-presentations, presentations, that can be reviewed, revisited, restructured and recognized, from multiple viewpoints" (Goldman, 2007, p.16). Video representations are different from more traditional data representations because they give form to the research experience as it occurs, instead of days, weeks, or months later.

Additionally, video representation makes use of multiple voices and vantage points. This emphasis of the multi-layered nature of language allows for the acknowledgement of multiple points-of-view. When considering research representations, video based representation and interpretation give openings for the consideration of viewer/maker relationships inherent in video creation, essentially inviting both maker and viewer into the representative and interpretive processes. Video is not a neutral medium simply capturing events as they occur, rather the videos we create in our research encounters are filled with multiple contexts and voices, all focused on the eventual creation of an artifact living both outside and within our inquiry. We find the ability to provide multiple perspectives contributes to productive, not reductive, inquiry. 
Researchers currently using video in their work have begun to postulate about the ways to enact video to invite the viewer into different spaces. Kaye Haw and Mark Hadfield (2011) conceptualize five modalities, or functions, for video as a research tool: extractive, reflective, provocation, participation, and voice. These five modalities have helped us envision our own video work as an invitation to extract, reflect, provoke, participate and speak. Using Greene's (1995) notion of the imagination and hook's (1990) idea of the imagination as a site of marginal resistance, we have begun to conceptualize video representation as an imaginative invitation to move into the margins and push up against traditional notions of research. We theorize that through imagination, video allows our audience to participate and collaborate in the interpretive work of inquiry with researchers.

Video as an invitation assumes the power of the moving image to provide a window into that which may not have been seen or heard otherwise. Whether the voice is that of children in a classroom (Haw \& Hadfield, 2011) or the experience of making and being with art (Eisner, 2008), video holds the potential to invite the viewer into spaces otherwise unseen. By giving voice to these unseen experiences of research, the researcher opens up spaces of inquiry for the viewer to create their own interpretations. This, we believe, is the sublime power of video in research; the ability to extend an invitation to the viewer/participant/audience to become a part of the research process. Video is familiar to us, accessible to a broad number of participants. We see this accessibility providing "transformations, openings and possibilities" (Greene, 1995 , p. 17) that allow our audience to move beyond our research, to push the reverberations of our inquiry into spaces with which others may engage.

In composing video, we layer images and text, data, themes, poems, prose, and other artwork ${ }^{5}$ together to create an experience for the viewer. We invite readers to experience the research encounter and begin to imagine their own interactions with our projects. This imaginative interaction puts trust in the reader/viewer; it takes the power of research out of the hands of researchers and places it into the hands of the audience (Greene, 1994). We do not create videos to convey one single, homogenized message, nor do we intend the audience to have an isolated interpretation. We see potential for multifaceted interpretation as the real role of video representation. We turn again to Greene's insights:

If realities are constructed...if meanings are created by living beings in diverse kinds of relationships, questions arise regarding representation that were seldom confronted before. We are not simply faced with the

\footnotetext{
${ }^{5}$ This layering effect is often referred to as assemblage. The examples of art forms we note are but a few of signifiers of the research experience.
} 
problem of deciding whether discourse functions to represent an objective or pre-existing reality...What is designated... is a condition of conception and perception that enables us to construct something we recognize...in our imagination...it is in no way a single thing, evoking either fixity or objectivity. (1994, p. 209-210)

Representation is not the result of our research endeavors; representation is not the outcome of our inquiry; rather, representation is what we do with our own understanding of the work - a process. Before we represent we interpret, after we represent you interpret and then represent again. The challenge in qualitative research is moving beyond the binaries of right and wrong, truth and fiction, positive and negative and into a space where representation becomes an invitation for the viewer/reader to take the researcher's interpretation into their own spaces, exist with it, and imagine other possibilities (Greene, 1994). So now, with Greene's idea of the imaginative invitation we ask: Do you want to watch a movie?

\section{Do you want to watch a movie?}

As co-authors, we have constructed a pair of manuscripts (the paper you are reading being one of the two) dealing with issues of representation from both ontological and methodological perspectives. We tell you this to clarify the goal of this section. Instead of discussing our own individual work with video, we chose to trade video data. Because we are both exploring how video-based data serves as an invitation to participate in the research process, we sought to explore the act of being invited to view someone else's inquiry. To achieve this we felt it was important to trade videos as we wrote about these ideas ${ }^{6}$. We hope this trading of video data will provide you, the reader, with insights gleaned by someone who is not the researcher (a task we challenge you to undertake as well).

You will find that we approach the analysis through a dialogic format. After watching Leslie's video, Sara explored the emergent meanings this mode of representative analysis presented. Once Sara completed her initial discussion, she then invited Leslie to respond to her reflections, providing additional clarity where needed. This process was repeated until we felt we had reached the end of our dialogue. As you read the following section we ask that you first watch the video; stop it, start it, pause it, fast forward it, open several windows, or even only listen to the audio. Then, scroll below the video to find a written analysis from Sara's perspective, another first time viewer, in tandem with Leslie's reflections on the process of editing, formatting and engaging in research using both video documentation and representation.

\footnotetext{
${ }^{6}$ This manuscript was written in tandem with another where Leslie is the first author and discusses, unpacks, and analyzes Sara's video work.
} 
https://ualberta.aviaryplatform.com/r/862b85474t

Mapping and Multiplicities, video courtesy of Leslie Rech

\section{Question 1: What is going on here?}

Leslie (on context) - I come to early childhood education from art education, a field in which talk about the work is as vibrant and compelling as the work itself. Exploring the tangle of visual and verbal references in children's drawing parallels one of my biggest challenges in making the switch from art to research: the place of images in a discipline in which writing is traditionally privileged. My interest in visual research methods began with an ethnographic case study in 2012-13 looking at the relationships between children and drawing, pop culture and identity. In this project, I worked with six 6, 7 and 8 year olds for eight months at a private Montessori school. I chose the site for its open curriculum and flexibility of classroom activities. During the project, the participating children and I drew together for 30-45 minutes each week exploring topics ranging from, bats, to battleships, to baseball.

Sara - What I find most powerful about this video is the reliance on the viewer. As Greene (2004) discussed, "whatever happens or is to happen has to be decoded; reader activity is necessary if meaning is to happen" (p. 213). From the minute the video started, I began filtering through questions:

Why are these children here?

What has prompted them to draw boats?

Do they know each other?

How did they connect their visual stories through talking so effortlessly?

What happens in the fade in and out moments?

I watched this video several times, fascinated by the stories the children made up about their drawings, in awe of how they connected their stories across papers. The narrative continues to circle around the table, with each child adding to the story. At the start, I found myself wanting to see more of the pictures, for there to be a way that pictures of their work might be next to the image of them working; then, after a soft fade I could see the children's work, while still seeing and hearing the dialogue. I felt like a fly, perched on the table, watching them draw and talk. They made up their stories so easily. Their artmaking was just an extension of the storytelling - effortless and collaborative. I cannot remember the last time I sat down and imagined a world outside my own; even my artmaking is grounded in reality, tinted by the colors of my day, week, or month. l'd love to know a bit more about the experience from your perspective.

Leslie - We are sitting at a battered picnic table outside the main classroom. I've laid out sheets of paper and a pack of scented markers. Today 
is Zanto's turn to choose the theme for our drawings. He's chosen Battleships. We talk it out as usual, tasting the words in our mouths, testing their meanings . . . battleship, battleship board-game, actual battle ship, Leggo battleship, wedding ship, evil alien ship. River, excited by the possibilities, begins her drawing with the color blue...

Sara - I was invited into this private moment as I watched, experiencing this video as a representative invitation, an invitation to view Leslie's documentation of a phenomenon (Haw \& Hadfield, 2011). I watched the video again, this time I knew what to expect. I could pause and really look at the drawings the children were making. I opened up the video in two windows on my computer and listened to the audio while I looked at the drawing, hoping to see the jet boosters, the battle, or the plastic people to which the children refer in their dialogue. I could stop and start, zoom in and turn the volume up and down; I could manipulate the video to allow myself the opportunity to reflect on what was happening. My invitation extended further, reflecting on the events as they occurred, after they occurred and while time was standing still (Haw \& Hadfield, 2011).

I was still not through my second viewing when I noticed Leslie at the table. What was she doing there? What questions was she asking when the camera faded in and out? How was her presence changing the reactions and conversations of the children?

I was critical of her presence, I played the end a few times, rewinding to the point in the video where the perspective changes and you can see the three children with Leslie's hands in the foreground. I began thinking of how I might have engaged in the conversation, and even further to thinking of how I engage in my own interactions with children.

She lets them talk so freely, not stepping over them with her own words. When one talks about peacekeepers in his drawing, she asks, "Where are they all?" The children respond: the peacekeepers cannot get on any ships. I want to know more about these peacekeepers. Who are they? What do they do? Where did they get the idea for them? I wonder if they mirror anything in the real world. My adult brain is constantly trying to make sense of the interactions and the storyline.

Leslie - I recorded each drawing activity with a small iPad-mini faced toward them so they could see what as I recorded. After I started the camera, I allowed it to run until the end of the activity. Over the course of the eight months I spent with them, ideas about ways children cite popular culture in their drawing narratives and then transform those narratives, continued to surface.

Sara - I felt provoked as I watched. I want to know more about these children and their motivations. I was even imagining how the dialogue might 
continue once the camera shut off. At this point, I have watched the video six or seven times. I think of the power of this video in isolation of any other research artifacts or contexts. I have moved through the first three modalities Haw and Hadfield discuss (2011), extractive, reflective, and provocative. Invitations to participate and speak were also extended, but not just to me. The children were invited to participate in the generation of a thirty-minute recording; they are performers and participants. The invitation to participate and give voice seems to occur on the other side of the camera. The children know the camera is recording them, they have been asked to create art. They are allowing us into their world of artmaking and storytelling. I do not have to guess at what these kids are drawing. The researcher did not have to conduct interviews asking them to think of what they were representing in their drawings, rather, the children have been invited to share these insights as they occur during the research process.

Leslie - I had intended a design that was open, flexible, and collaborative, one focused on following data as opposed to erecting a structure for it to exist within. For example, rather than formal interviews, I used informal drawing activities that allowed the children in the study to plan their own drawings, to choose their own pseudonyms, to see themselves recorded. On reflection, the design was flawed in that the activities I designed for data collection were just that, designed, not nomadic. A nomadic practice would have followed children in their daily drawing activities rather than invite them to the table for that specific purpose, but this project also allowed me to see that I had not yet considered analysis itself as a nomadic practice.

\section{Question 2: What are the emergent ideas from this video?}

Sara - While the video in isolation of other contexts is interesting, the research is aimed also at the emergence of new ways of thinking about or understanding something. So my next question during this analytic unpacking is: What is that something? My first thought revolves around the role talk plays in children's drawing practice. This video is filled with conversation about the imaginary goings on of the children's drawings. The children seem to be making meaning not just through their drawings, but through the stories they are telling as they draw. But would this have occurred without Leslie there? Does that matter? I wonder what role the surrounding contexts play? There are bigger questions begging consideration, contextual understandings that are necessary to really grasp what is happening below the surface.

Leslie - In research, "collecting" data, identifying, naming, defining, interpreting, abstracting, reducing events, is akin to what Deleuze and Guattari (2004) would call a tracing: "like a photograph or an X ray that begins by selecting or isolating by artificial means such as colorations or other restrictive procedures, what it intends to reproduce" (p. 13). In describing and transcribing an event, we will always be reducing it, cutting it from its context. To address this 
reduction, Deleuze and Guattari (2004) suggest consideration of the concept of mapping, rather than tracing. A tracing tends to pin or immobilize. A map follows contours, makes connections.

In this project, mapping meant looking at children, their drawings, their classroom and local cultural discourses, the materials in play, the space in which all these things unfolded and the events that occurred as data. Mapping became a strategy for analysis that informed a juxtaposition of ideas and images based on threads of connection. These juxtapositions add to the multiple ways in which the data can be interpreted. Video composition functions as a multiplicity, a permeable analysis that forestalls interpretation. Specifically, video editing, the selecting and juxtaposing of film clips or "shots," works as a nomadic practice in that placing images in relation to one another makes connections visible, cuts them loose from more over-determined meanings. These juxtapositions add to the ways in which data can be read. I see the possibilities of video composition not as an illustration of text but as a nomadic visual/relational analysis.

\section{Question 3: What about editing decisions?}

Sara - As an invitation, the video has served its purpose by enacting interest, drawing the viewer into the experience of being with these children. Leslie's video has successfully provided a glimpse of the setting and participants, while also giving the viewer a felt, or sensory context to pull from. While these factors are effective in inviting the viewer into the research, additional context is necessary to deeply grasp the research project itself. Additionally, when working with video in research practice, we make choices about how to edit reality; we curate the viewer's experience. It is this curation I am now interested in knowing more about. Why did Leslie choose the slow fades in and out? Was she influenced by the ghost images present in Celeste Snowber's (2012) work? Why did she use black and white imagery? I wonder why she chose to have the fades between images of children and their artwork not last longer. Kip Jones (2011) chooses to have stills of photographs fade in and out with narration over the images. This might have been an effective way to show more of the children's art, while still allowing their stories to be heard. These are the questions I am left with after watching the video, so these are the questions I pose to you Leslie.

Leslie - MacDougall (1998), an anthropologist and documentary filmmaker, suggests that viewers are prone to assigning meaning quickly to moving images. He calls this a fertile process:

... the images of the film interacting with the characteristics of personality, culture, and society that define us. This means that shots may carry quite different connotations even for people of very similar background, and larger differences of gender, class, race, and education will produce even greater variations. (p. 212) 
For this reason he advocates the long shot in film - a longer, uninterrupted version of the shot, contextual and undiluted with either text or voiceover. This provokes what he calls "digressive searching" in viewing, an active rather than passive meaning making by the viewer (p. 213).

MacDougall (1998) argues that contemporary filmmakers try hard to avoid "dead spots" or places in the film where nothing seems to be happening, places where the viewer's attention gets lost. He also suggests that in figure-ground reversals, shots in which the protagonist dissolves into context, the viewer's focus again is allowed to wander. MacDougall argues that today, the immediacy and fast pace of popular television commercials and music videos may actually allow more room for associative, non-narrative editing in that there is less reliance on the narrative. He suggests that unexplored possibilities for visual research exist within the layering of sound and image as well as in an analytical use of the camera.

MacDougall (1998) does bring up a concern about audience attention for longer films constructed with lengthier shots. He suggests the concept of segmentation: shorter films focusing on sub-groups of connections, as a strategy for keeping the viewers attention. The dead space in a long shot to which MacDougall refers, the spaces in watching a film where the mind begins to wander, may work for research-oriented videos. I see a parallel here between what MacDougall is calling segmentation, a sub-group of possible interpretations, and the idea of nomadic analysis. I think it would be productive to allow space for the viewer to get lost from time to time in our research. With this in mind, I composed my video, making use of MacDougall's preference for the long shot, the dead spot and figure-ground reversals. In this composition, I focused less on the arc of one analytic theme and focused more on looser, less visible connections to allow room for the viewer (and myself) to wander.

Your question revolves around the media itself as an abstraction. Video recordings are distillations of reality; a perspective extracted, cut from context, and preserved - what Mohl (2011) identifies as "semantic densification" (p. 233). Garrett and Hawkins (2014) agree that video recording and editing as a method is potentially reductive, but that creative use of video necessarily complicates these methods ( $p .145$ ). They also argue that editing is a productive process and see video composition less as cutting or reducing data and more as "thematic excavation, the concentration of concepts, the intensification of ideas, and the refinement of trajectories" (p. 156).

There is no doubt that video as a research medium is both accessible and affective. It collides with its audience in rich, complex, and compelling ways. 


\section{Conclusion}

Video representation is a process. It is through camera lens and later the editing screen that we begin to re-search and re-present. Re-search and representation are no longer things - they are process-based movements (Goldman, 2007). When we capture movements, pair them with sound, color, light, and multiple vantage points, we begin to grasp at the process of research encounters. Video, as an imaginative invitation, challenges how we conceive of research, representation, and interpretation. By documenting the movements of our research, we allow ourselves to re-search our data for insight and create representations of these affective experiences. The videos we create in our work re-present our data repeatedly, each time allowing for a new consideration, new perspective, and new interpretation. This is an important step in reimagining the role of representation in the research processes. Garrett \& Hawkins (2014) and others refer to this as "more-than-representational inquiry" (p. 145). By envisioning the video as an imaginative invitation, we open up spaces for others to enter into our inquiries. We create artifacts of inquiry that do more than just represent our findings. We no longer hide the movements of our research in locked filed cabinets; rather, we layer and juxtapose these to create an affective experience for our reader/viewer. Jungnickel (2014) discusses this process as opening up the thereness of experiences. By creating artifacts that speak to the thereness of experiences, we begin to transform the nouns, research, and representation, into verbs, re-search and re-present. We move our research into the margins, where bell hooks (1990) invites us to engage in radical openness:

A message from that space in the margin that is a site of creativity and power...Enter that space. Let us meet there. Enter that space. We greet you as liberators. Spaces can be real and imagined. Spaces can tell stories and unfold histories. Spaces can be interrupted, appropriated, and transformed through artistic and literary practice...we are transformed, individually, collectively, as we make radical creative space which affirms and sustains our subjectivity, which gives us a new location from which to articulate our sense of the world. (p. 24)

We believe in the spaces of radical openness in which we might begin to open up dialogue that looks deeply at experiences and attempts to represent those experiences through video methods that challenge our ontological understandings of the world.

Like all other forms of inquiry, we believe the work of video researchers takes practice and skill development. This is not a point and shoot methodology, rather this is a layered and complex approach to reconfiguring our research encounters. We have found that engaging in video production has challenged our underlying assumptions about what it means to record and represent research. In addition to the complexity faced in recording, cutting and editing, the work of video researchers opens up discussions of the ethics of this methodology 
(Bates, 2014; Goldman, Pea, Barron, \& Derry, 2014; Haw \& Hadfield, 2011). Video does not satisfy or give resolution; it does not make finite statements or tie inquiry up in a neatly trimmed package. While video is not appropriate for all research projects, we see it creating openings for consideration by challenging what research looks like. Video research does not symbolize experiences; rather, it allows the viewer to make their own experience. It invites viewers into inquiry by opening up access, encouraging collaborations and promoting productive, not reductive, dialogue.

We hope you, the reader, will respond to our invitation, and begin to experiment with the video as representation in your own inquiries. In alignment with our avoidance of singular endings or interpretations, we leave you with a series of questions you might consider in constructing your own video invitations to engage in inquiry:

- How might video add another layer of understanding to your work?

- How might video open up spaces for critical topics to be explored and questioned?

- What might emotional reactions to video assemblages do for our research projects?

- How can video provide new artful representations of research inquiries?

- Can video successfully shift the power of knowing away from the researcher and into the hands of the viewer/reader?

- In what ways can video push our research into spaces for new audiences to experience it?

These are the questions we that moved us to consider the role video can play in our own inquiries. These are the questions we invite you to consider in your own work to change what we mean when we read research and say, "I know. I understand". We hope that you will embrace the messiness and refocus the outcomes of research representations by reimagining possibilities, but most of all we hope you will ask others, "Do you want to watch a movie?"

\section{Acknowledgements:}

The authors would like to extend a special thank you to River, Zanto, and Moton $B$. for their joyful participation, imagination and collaboration on this project. 


\section{References}

Bakhtin, M. M. (1982). The dialogic imagination: Four essays. (M. Holquist, Ed.; C. Emerson, Trans.) (reprint ed.). Austin, TX: University of Texas Press.

Barone, T., \& Eisner, E. (1997). Arts-based educational research. In R. M. Jaeger (Ed.), Complementary methods for research in education (pp. 75116). Washington, DC: AERA.

Bates, C. (2014). Video methods: Social science research in motion. New York, NY: Routledge.

Chambers, C., Hasebe-Ludt, E., Donald, D., Hurren, W., Leggo, C., \& Oberg, A. (2008). Métissage: A research praxis. In J. Knowles \& A. Cole (Eds.), Handbook of the arts in qualitative research: Perspectives, methodologies, examples, and issues (pp. 142-154). Thousand Oaks, CA: Sage.

Deleuze, G., \& Guattari, F. (2004). A thousand plateaus: Capitalism and schizophrenia. London, UK: Continuum.

Dewey, J. (1934). Art as experience. New York, NY: Minton Balch \& Company.

Eisner, E. W. (1997). The promise and perils of alternative forms of data representation. Educational Researcher, 26(6), 4-10. doi: 10.3102/0013189X026006004

Eisner, E. W. (2008). Art and knowledge. In J. Knowles \& A. Cole (Eds.), Handbook of the arts in qualitative research: Perspectives, methodologies, examples, and issues (pp. 3-13). Thousand Oaks, CA: Sage.

Fish, S. E. (1980). Is there a text in this class?: The authority of interpretive communities. Cambridge, MA: Harvard University Press.

Flaherty, M. G., Denzin, N. K., Manning, P. K., \& Snow, D. A. (2002). Review symposium crisis in representation. Journal of Contemporary Ethnography, 31(4), 478-516. doi: 10.1177/0891241602031004004

Garrett, B. L., \& Hawkins, H. (2014). Creative video ethnographies. In C. Bates (Ed.), Video methods: Social science research in motion (pp. 142-160). New York, NY: Routledge.

Goldman, R. (2007). Video representations and the perspectivity framework: Epistemology, ethnography, evaluation, and ethics. In R. Goldman, R. Pea, B. Barron, \& S. J. Derry (Eds.), Video research in the learning sciences (pp. 3-37). New York, NY: Routledge. 
Goldman, R., Pea, R., Barron, B., \& Derry, S. J. (2014). Video research in the learning sciences. New York, NY: Routledge.

Greene, M. (1991). Texts and margins. Harvard Educational Review, 61(1), 2740.

Greene, M. (1994). Postmodernism and the crisis of representation. English Education, 26(4), 206-219.

Greene, M. (1995). Releasing the imagination: Essays on education, the arts, and social change. San Francisco CA: Jossey-Bass Publishers.

Greene, M. (2001). Variations on a blue guitar: The Lincoln Center Institute lectures on aesthetic education. New York, NY: Teachers College Press.

Greene, M. (2005). Teaching in a moment of crisis: The spaces of imagination. The New Educator, 1(2), 77-80.

Haw, K., \& Hadfield, M. (2011). Video in social science research: Functions and forms. Abingdon, UK: Taylor \& Francis.

hooks, bell. (1990). Yearning: race, gender, and cultural politics $\left(1^{\text {st }}\right.$ ed). Boston, MA: South End Press.

Irwin, R. L., Kind, S. W., \& Springgay, S. (2005). A/r/tography as living inquiry through art and text. Qualitative Inquiry, 11(6), 897-912.

Jones, K. (2011) Rufus stone. [Video]. Retrieved from: https://vimeo.com/109360805.

Jungnickel, K. (2014). Jumps, stutters and other failed images: Using time-lapse video in cycling research. In C. Bates (Ed.), Video methods: Social science research in motion (pp. 121-141). New York, NY: Routledge.

Knowles, J. G., \& Cole, A. L. (Eds.) (2008). Handbook of the arts in qualitative research: Perspectives, methodologies, examples, and issues. Los Angeles, CA: SAGE Publications, Inc.

Leavy, P. (2015). Method meets art: Arts-based research practice $\left(2^{\text {nd }}\right.$ ed). New York, NY: Guilford Publications.

Lincoln, Y. S., \& Denzin, N. K. (1994). The fifth moment. In N. K. Denzin \& Y.S. Lincoln (Eds.), Handbook of qualitative research, (pp. 575-586). Thousand Oaks, CA: Sage. 
Marcus, G. E., \& Fischer, M. M. J. (1986). Anthropology as cultural critique: An experimental moment in the human sciences. Chicago, IL: University of Chicago Press.

MacDougall, D., \& Taylor, L. (1998). Transcultural cinema. Princeton, NJ: Princeton University Press.

McLuhan, M., \& Fiore, Q. (1967). The medium is the message. In G. Durham, \& D. Kelnner (Eds.), Media and cultural studies: Keyworks (revised ed.) (pp. 126-128). Malden, MA: Blackwell Publishing Ltd.

McNiff, S. (1998). Art-based research. London, UK: Jessica Kingsley Publishers.

McNiff, S. (2008). Art-based research. In J. Knowles \& A. Cole (Eds.), Handbook of the arts in qualitative research: Perspectives, methodologies, examples, and issues (pp. 29-41). Thousand Oaks, CA: Sage.

Pink, S. (2001). Visual ethnography: Images, media and representation in research. London, UK: Sage.

Rabinow, P. (1986). Representations are social facts: Modernity and postmodernity in anthropology. In J. Clifford \& G. E. Marcus (Eds.), Writing culture: The poetics and politics of ethnography, (pp. 234-261). Berkley, CA: University of California Press.

Rolling, J. H. (2013). Arts-based research primer. New York, NY: Peter Lang Publishing.

Schön, D. A. (1983). The reflective practitioner: How professionals think in action (vol. 5126). New York, NY: Basic books.

Snowber, C. (2012). BodyPsalms [Website]. Retrieved from: http://bodypsalms.com/

van Maanen, J. (1995). Representation in ethnography. Thousand Oaks, CA: Sage Publications, Inc. 